\title{
The Hidden Talents of Underachievers through Counselling
}

\author{
Dr. T. Sumalini ${ }^{1}$, K. Appaji ${ }^{2}$ \\ ${ }^{1}$ Assistant Professor, Department of Education and Education Technology, \\ University of Hyderabad \\ ${ }^{2}$ Research Scholar, Department of Education and Education Technology, \\ University of Hyderabad,
}

\begin{abstract}
Originality cannot be determined through outer appearance as there are some hidden qualities behind every individual. In the education process, one cannot judge the actual capacity of learners. Many times No one can estimate the student's abilities in the classroom without knowing their inner talent. Every individual is talented by birth; if the inner talents are not recognized it would be a great loss to the system when the hidden talent of an underachiever has been identified and enriched so that they can reach great heights, and that could be the happiest movement for a child as well as their parents. Counselling is one of the best techniques to find out the hidden talents of an individual. It would be an irrefutable and substantial contribution to the nation by recognizing the talent in a person.
\end{abstract}

Keywords: originality; estimate; irrefutable; underachiever; hidden talent 